\title{
Sexual knowledge in adolescents with intellectual disabilities: A timely reflection
}

\author{
Becky Rowe \\ Griffith University \\ Courtney Wright \\ Griffith University
}

\begin{abstract}
At its core, sexuality education for adolescents with intellectual disabilities (ID) is an international human rights issue. Adolescents with ID have the same sexual desires and needs as others, yet their sexuality is generally portrayed as problematic. Despite an ideological shift towards normalisation and inclusion of people with disabilities, sexuality education for adolescents with ID remains an under-explored field. The current article presents an informed literature review of the factors that influence the effectiveness of sexuality education on sexual knowledge among adolescents with ID, and an accompanying commentary on how these factors sit within wider disability studies and practice. As will be shown, the available evidence on sexual knowledge in adolescents with ID reports on sexuality education sources and delivery, sexual knowledge, conservative curricula, and social exclusion. This review of contemporary research from developed, westernised countries identifies important implications for policy, practice, and future research. This article is significant and timely given the disjunct between the current expression of sexuality in young people with ID and recent international human rights actions to promote both the rights of people with disabilities and sexuality education rights for all adolescents.
\end{abstract}

Keywords: sexuality, education, human rights, curriculum, social exclusion, youth

Sexuality is a fundamental part of being human. Adolescents with intellectual disabilities (ID) ${ }^{1}$ have the same sexual desires and needs as everyone else, yet their sexuality is generally portrayed as problematic (Plaks et al., 2010). Despite an ideological shift towards normalisation and inclusion of people with disabilities (Evans, McGuire, Healy, \& Carley, 2009), sexuality education for adolescents with ID remains an under-explored field. At its core, sexuality education for adolescents with ID is an international human rights issue. Sexuality education is essential to meet all adolescents' right to access adequate information to protect their health, development, and participation in society - including sexual and reproductive information - as per the United Nations (UN) Convention on the Rights of the Child (United Nations Educational, Scientific and Cultural Organisation (UNESCO), 2009). Moreover, the UN Convention on the Rights of Persons with Disabilities (UNCRPD) stipulates the rights of people with disabilities to receive accessible sexual and reproductive education, without discrimination (UN, 2008). Although great strides have been made since

\footnotetext{
${ }^{1}$ ID is defined by the American Association on Intellectual and Developmental Disabilities as being characterised by "significant limitations both in intellectual functioning and in adaptive behaviour as expressed in conceptual, social, and practical adaptive skills. This disability originates before age 18" (Schalock et al., 2010).
} 
the recent history of forced institutionalisation, sterilisation, and sexual segregation of people with ID (Gomez, 2012), the full sexual rights of people with ID are yet to be realised; evidenced, for example, by the blanket use of long-term contraception in young women with ID (Gougeon, 2009).

High levels of sexual abuse within the ID population are potential indicators of poor sexuality education for this group. Women with ID are significantly more likely to experience rape, unplanned pregnancy, reproductive rights violations (Frawley \& Wilson, 2016), sexual abuse, and mental health problems associated with abuse (Eastgate, Van Driel, Lennox, \& Scheermeyer, 2011) than non-disabled women. Men with ID are at far greater risk of contracting sexually transmitted infections, and being convicted of sexual offences than are other men (Frawley \& Wilson, 2016). Correlations are frequently made in the literature between these high rates of sexual abuse and low levels of sexual knowledge in people with ID (Dukes \& McGuire, 2009; Eastgate et al., 2011; Frawley \& Wilson, 2016). Low levels of sexual knowledge are commonly cited in young people with ID (Pownall, Jahoda \& Hastings, 2012). While research on sexuality education interventions for people with ID generally lacks methodological rigour, the results seem to indicate positive improvements in sexual knowledge following such programs (McGuire \& Bayley, 2011). To safeguard young people with ID from becoming victims or perpetrators of sexual abuse, it seems pertinent to evaluate their levels of sexual knowledge under current sexuality education programs.

Previous studies have explored sexuality education and sexual knowledge for people with $I D$, however, few have focused specifically on the experiences of adolescents. A recent systematic review has shown that sexuality education for people with ID must be improved to increase sexual knowledge, but the review includes only a small fraction of studies with an adolescent population (McDaniels \& Fleming, 2016). Other studies have derived data on adolescent sexual knowledge through parents' observations and opinions of their adolescents' behaviour (Ginevra, Nota, \& Stokes, 2016; Isler, Tas, Beytut, \& Conk, 2009; Pownall, Jahoda, Hastings, \& Kerr, 2011). Further conceptualisations of sexual knowledge in adolescents with ID have stemmed from teachers' perceptions (Ang \& Lee, 2016; BarnardBrak, Schmidt, Chesnut, Wei, \& Richman, 2014). There is a noticeable dearth of research on sexual knowledge and understanding among adolescents with ID from their own perspective.

The cultural context surrounding sexuality and sexual knowledge varies significantly across the globe, reflective of the differing health concerns, and socio-political situations of particular countries. In South Africa, for example, HIV/AIDS is a leading cause of death (World Health Organisation (WHO), 2017). As such, South African research on sexuality education for adolescents with ID focuses on their comprehension of sex in relation to the contraction of HIV/AIDS through sexual intercourse (Dawood, Bhagwanjee, Govender, \& Chohan, 2006). In terms of socio-political circumstances, a Turkish study has shown that $75 \%$ of parents of adolescents with ID had no formal sexuality education themselves, with nearly half learning the basics from their husband and wife. Parents play a key role in educating their children, and the parental lack of sexual knowledge affects the knowledge of their adolescents with ID (Isler, Beytut, Tas, \& Conk, 2009). It follows that sexuality education for adolescents with ID must be understood within the cultural discourse of those adolescents' life worlds.

The current article presents an informed literature review of the factors that influence the effectiveness of sexuality education on sexual knowledge among adolescents with ID, and an accompanying commentary on how these factors sit within wider disability studies and practice. This review of contemporary research from developed, westernised countries identifies important implications for policy, practice, and future research. As will be shown, the available evidence on sexual knowledge in adolescents with ID reports on sexuality education sources and delivery, sexual knowledge, conservative curricula, and social 
exclusion. This article is significant and timely because there is a disjunct between the current expression of sexuality in young people with ID and recent international human rights actions to promote both the rights of people with disabilities and sexuality education rights for all adolescents. To uphold the human rights imperative of providing sexuality education for people with disabilities per the same standards as others, and influence disability practice and policy surrounding sexuality education for adolescents with ID accordingly, the factors impacting this pedagogy must be analysed. From the analysis, future directions can reasonably be suggested for more comprehensive sexuality education for adolescents with ID through the design, content and delivery of programs.

\section{Sources and delivery of sexuality education}

Sexuality programs at school appear to be the predominant source of sexuality information for adolescents with ID (Corona, Fox, Christodulu, \& Worlock, 2016; Healy, McGuire, Evans, \& Carley, 2009; Jahoda \& Pownall, 2014; Löfgren-Mårtenson, 2012; Tissot, 2009). Adolescents with ID reportedly received significantly less sexual information from doctors than their non-disabled peers; while both groups of teens received sexual information from the media (Jahoda \& Pownall, 2014). Some students also gained sexual information from friends (Löfgren-Mårtenson, 2012), more commonly males with ID than females with ID. Adolescents with ID tended to have smaller social networks which included more family members than non-disabled adolescents (Jahoda \& Pownall, 2014). However, some adolescents with ID have reported not being able to remember whether they had sexuality education. Several adolescents were only able to identify sexuality education when it was described as splitting into gender groups, and others reported their education was "too little or too difficult to understand" (Löfgren-Mårtenson, 2012, p214).

A number of teaching methods have impacted adolescents with ID's experiences of sexuality education within schools. In students with mild to moderate ID, small, gender-divided groups have been perceived positively (Löfgren-Mårtenson, 2012), but adolescents with severe ID appear to respond well to individualised programs (Tissot, 2009). Verbal delivery of sexuality education - including complex questions, multiple-choice questions, and the use of conditional clauses - have reportedly contributed to poor comprehension in this group (Finlay, Roehlder, Taylor, \& Culfear, 2015). Adolescents with ID seemed to learn better from visual materials, visual activity schedules (Corona et al., 2016), audiobooks, TV shows, roleplaying activities, pantomime-style theatre (Löfgren-Mårtenson, 2012), and visual aids (Tissot, 2009). Specifically, Picture Exchange Communication System (PECS) and visual pictures depicting steps (jigs) were found to be effective in non-verbal adolescents with ID (Tissot, 2009). According to the literature, students with ID tended to create a superficial indication of comprehension due to teacher prompts, suggestive rephrasing, automatic 'yes' answers, guessing, and copying the teacher or other students (Finlay et al., 2015). Sexuality education that was concurrently delivered at home and school was found to be effective in two studies (Corona et al., 2016; Tissot, 2009).

The aforementioned authors theorised that adolescents with ID do not retain the information presented in sexuality education due to inappropriate teaching modalities (Corona et al., 2016), such as reliance on verbal explanations for abstract concepts (Finlay et al., 2015). Sexuality education therefore ought to be tailored (Healy et al., 2009), potentially on an individual level, as the group setting makes it difficult to cater to a wide range of knowledge levels (Corona et al., 2016), and reduces the educator's ability to ensure individuals have understood (Finlay et al., 2015).

\section{Sexual Knowledge}

Adolescents with ID reportedly understand the physical changes that occur during puberty (Corona et al., 2016), with some expressing that sexual anatomy and contraception were their main areas of sexual knowledge (Löfgren-Mårtenson, 2012). Corona et al. (2016) reported that many of their research participants understood how reproduction works. 
Additional studies found that adolescents with ID had a positive perception of masturbation and understood its private nature (Healy et al., 2009), and acknowledged the risks of the internet in regards to sexuality and relationships (Löfgren-Mårtenson, 2012). A study by Jahoda and Pownall (2014) found notable gender differences in sexual knowledge, with males with ID possessing greater levels of knowledge than females with ID, the inverse of what occurs in adolescents without ID (Jahoda \& Pownall, 2014). The bulk of sexual knowledge was understood from a heterosexual point of view only (Löfgren-Mårtenson, 2012).

Despite these findings, there were more incidences of adolescents with ID misunderstanding sexuality concepts, indicative of an overall lack of comprehension (Finlay et al., 2015). Adolescents with ID showed significantly lower sexual knowledge than non-disabled adolescents in all areas (Jahoda \& Pownall, 2014). The most frequent misconceptions occurred in relation to contraception and sexually transmitted diseases (STDs) (Corona et al., 2016; Healy et al., 2009; Jahoda \& Pownall, 2014). For example, Jahoda and Pownall (2014) found that 29 out of 30 adolescents with ID misunderstood how the contraceptive pill works, and that many could not name any STDs. Other areas of lacking knowledge included sexual hygiene (Corona et al., 2016) and sexual intercourse (Jahoda \& Pownall, 2014). Sexual intercourse was perceived by some adolescents with ID as inappropriate or forbidden (Healy et al., 2009). Poor knowledge on reproduction (Healy et al., 2009; LöfgrenMårtenson, 2012), and sexual anatomy (Healy et al., 2009) was also observed, in contrast to the understandings presented above. Despite the desire of most adolescents with ID to have romantic relationships, they had very little knowledge on how to pursue intimate or romantic relationships (Corona et al., 2016; Healy et al., 2009), and wished to learn more about intimacy (Löfgren-Mårtenson, 2012). Adolescents with ID only understood sexuality from a heterosexual point of view; by omission, they did not understand alternative views on sexuality and gender (Löfgren-Mårtenson, 2012). The concepts of private and public were also misunderstood in relation to sexuality and relationships, even when privacy was understood in other aspects of life, like toileting (Corona et al., 2016). The distinction between private and public was therefore a key misunderstanding for non-verbal adolescents with severe ID (Tissot, 2009). It should be noted, however, that the absence of a robust and standardised measure makes it difficult to translate adolescents' knowledge levels across studies (Corona et al., 2016).

\section{Conservative Curricula}

According to Johada and Pownall (2014), sexuality education for adolescents with ID is commonly presented with a negative or narrow focus, with a tendency to address sexuality from a clinical, biological view rather than exploring issues of sexual pleasure, love, intimacy, and desire (Löfgren-Mårtenson, 2012). Motivated by concerns for protecting adolescents with ID, an overly-restricted sexuality education means this population becomes overprotected (Löfgren-Mårtenson, 2012). The overprotection of adolescent girls with ID leads to lower levels of sexual knowledge, which has been identified by Jahoda and Pownall (2014) as particularly counter-productive. In addition, most adolescents with ID had conservative views of their own sexuality and an observed low tolerance of homosexuality (Healy et al., 2009). This finding coincides with the heteronormative nature of the sexuality education students with ID received. To increase understanding of sexual diversity in adolescents with ID, it can therefore be argued that curricula ought to take a more critical approach to social, gender, and sexual norms (Löfgren-Mårtenson, 2012).

\section{Social Exclusion}

Social exclusion of adolescents with ID due to limited social networks and the assignment of "child-like" social roles was seen to contribute to poor sexual knowledge (Jahoda \& Pownall, 2014). As social exclusion is a main driver for the lack of sexual knowledge in this population (Tissot, 2009), school-based sexuality education seems crucial in assisting adolescents with ID develop a sexual identity. People with disabilities have faced a long history of eugenics, 
sexual segregation, forced sterilisation and marital prohibition (Gomez, 2012); remnants of which are still systematically entrenched through insufficient sexuality education for adolescents with ID. As above, adolescents with ID are less likely to receive sufficient sexual knowledge from health and education professionals than their peers. Restrictive sexuality education curricula and policies serve to further exclude adolescents with ID by diminishing their capacity for self-determination (Travers, Tincani, Whitby, \& Boutot, 2014), that is, the right to choice and control over their sexual life through lack of sexual knowledge.

\section{An integrated synthesis}

The following synthesis has been framed within contemporary disability studies theory and practices to enable disability researchers, practitioners, educators, and policy makers to improve sexuality education for adolescents with ID. The findings can help shape the delivery, content and design of sexuality education programs for adolescents with ID to a more socially inclusive end.

\section{The delivery style of sexuality education is crucial for comprehension}

It is not the presence of sexuality education that is lacking for adolescents with ID, but the comprehension of such sexuality education. Despite the finding that many adolescents with ID received sexuality education, there is a clear dearth of sexual knowledge observable in this population. The gap between sexuality education and sexual knowledge appears to be a result of inappropriate teaching modalities and learning environments.

Firstly, in terms of learning environments, the capacity of group-based programs to deliver the appropriate level of sexuality education for individuals across a wide range of cognitive functions and experience levels is unclear. Some studies report positive effects of groupbased learning (Löfgren-Mårtenson, 2012), while others stress the importance of individualised approaches (Corona et al., 2016; Finlay et al., 2015). As the results differ across sample groups, it may be that the suitability of group-based, versus individualised, sexuality education must be determined on an individual needs basis.

Secondly, in relation to teaching modalities, the available evidence indicates that visual materials work better than verbal explanations to increase sexual knowledge understanding in adolescents with ID. Sexuality education for adolescents with ID should, therefore, be delivered using a range of effective visual methods to increase the level of sexual knowledge. If the issue with developing sexual knowledge lies in the educational delivery methods, facilitators can reasonably draw from the greater body of knowledge on special needs education techniques. In support of visual materials, a recent systematic review on visual activity schedules has confirmed their efficacy as evidence-based practice in teaching people with ID over the age of 11 (Spriggs, Mims, van Dijk, \& Knight, 2017). Moreover, visual teaching aids can help educators determine whether students with ID have understood the sexuality education delivered. The use of picture response cards has been shown to increase classroom engagement levels of students with ID, helping these adolescents to better communicate their level of understanding to their teacher (Clarke, Haydon, Bauer, \& Epperly, 2016). Evidence-based teaching methods for adolescents with ID are especially important in sexuality education if these students are to understand the sexual knowledge presented to them and benefit from this education.

\section{School-based sexuality education is the main source of sexual information for adolescents with ID}

Research studies have indicated that school-based sexuality education is the primary source of sexual information for adolescents with ID, who rarely get sexual information from other sources, including friends, family, and doctors. As schools are currently the main provider of 
sexuality education, the onus appears to be upon them to provide a comprehensive curriculum which encourages adolescents with ID to develop their sexual knowledge.

Sources of sexual knowledge for adolescents with ID can be well framed using ecological systems theory, as Jahoda and Pownall (2014) have done. Ecological systems theory posits that a person's development hinges on the systems of which they are a part - including family, school, peer-group, policy and legal systems - and the interactions between these systems (Friedman \& Allen, 2011). Using a systems approach, adolescents with ID placed more emphasis on their family network, and were more likely to include teachers in their inner circles than their non-disabled peers, who were more likely to emphasise the importance of friendship groups (Jahoda \& Pownall, 2014). If adolescents with ID are mainly receiving sexual information from school programs, systems theory implies that the development of sexual knowledge would be hindered due to a lack of sexuality education in other systems. This position is supported by several scholars (Corona et al., 2016; Dupras \& Dionne, 2014; Ginevra et al., 2016; Isler et al., 2009; Tissot, 2009) who detail the importance of concurrent sexuality education by family members in the home for increasing sexual knowledge in adolescents with ID. From a systems perspective, school-based sexuality education alone is insufficient in providing adolescents with ID with sexual knowledge.

It has been established that adolescents with ID receive less sexual information from their friends than non-disabled adolescents. In line with systems theory, adolescents with ID are missing out on what Gougeon (2009) calls the ignored curriculum - the information casually exchanged between peers outside of class - due to factors like segregated schools, separate classrooms and schedules, and high levels of adult supervision. Moreover, the ignored curriculum in peer networks interacts with the other systems governing adolescents with ID. For example, mothers of children with ID have confirmed that their offspring did not have the opportunities to develop sexually and socially with their peers, so they withheld sexual information in fear of their children feeling upset and anxious if they knew what they were missing (Pownall et al., 2012). At present, the reliance on schools alone to provide sexuality education for adolescents with ID has had a detrimental effect on their overall level of sexual knowledge.

\section{Sexual knowledge is superficial}

In adolescents with ID, sexual knowledge is limited to elementary understandings of puberty, sexual anatomy, and reproduction that are inconsistent at best. This group misunderstands most real-life issues related to sexuality including STDs, sexual intercourse, contraception, pregnancy, relationships, intimacy, consent, and the distinction between public and private conduct. Adolescents with ID have expressed their desire to learn about intimacy, friendship and relationships, especially (Löfgren-Mårtenson, 2012). To provide a comprehensive sexuality education for adolescents with ID, the curricula must stop focusing on sex as a biological imperative, and begin framing sexuality as an intrinsic part of being human, consistent with international human rights. For two decades now, authors on the topic have contended that sexuality education for people with ID should address emotional and social aspects of sex and relationships (Garwood \& McCabe, 2000). In the years since this position was established, UNESCO has advanced a sexuality education agenda (UNESCO, 2009), and the UNCRPD has established the rights of people with ID to access such education (UNCRPD, 2008). However, despite human rights and academic advocacy efforts, this review has revealed that sexual knowledge in adolescents with ID is still lacking in the same spheres.

\section{Conservative curricula increase social exclusion}

Sexuality education curricula for adolescents with ID are negatively framed, conservative, and restrictive in their content. However, research on this topic has revealed that adolescents with ID's sexual knowledge is insufficient to experience their right to sexuality, thus increasing their social exclusion. As described above, school-based sexuality education 
is the primary source of sexual knowledge for adolescents with ID, which highlights the role of the curricula in this dynamic.

Given that low levels of sexual knowledge are associated with high rates of sexual abuse and STD contraction (Eastgate et al., 2011; Frawley \& Wilson, 2016), effective sexuality education for adolescents with ID has important implications for health and human services outside of the disability and education sectors. Research on reported rapes of women in Australia indicates the proportion of rape victims with intellectual disabilities is over eight times higher (Frawley \& Wilson, 2016) than in the general population (Australian Bureau of Statistics (ABS), 2014). Mental health professionals are required to deal with mental illness and sexual dysfunction associated with this abuse (Eastgate et al., 2011), and hence bear the responsibility of providing reactive sexuality education for people with ID.

Conservative and restrictive sexuality education curricula are likely a sign of overprotectiveness. It is difficult for parents to engage in sexuality education with their adolescents with ID, as they are often in a more dependent, child-like social role (Jahoda \& Pownall, 2014). Likewise, professionals tend to construct people with ID as desexualised, eternal children who are vulnerable, especially in relation to sexual activities (Starke, Rosqvist, \& Kuosmanen, 2016). The desire to protect people with ID is not unfounded, given they are at a significantly increased risk of sexual abuse (McDaniels \& Fleming, 2016). However, restricted sexual knowledge increases, rather than decreases, vulnerability to sexual crimes (O'Callaghan \& Murphy, 2007). Research has shown that sexuality education can increase the capacity of individuals with ID to make informed sexual decisions (Dukes \& McGuire, 2009). The bid to protect adolescents with ID from sexual harm by limiting their sexuality education, then, is counter-productive and may contribute to the high rates of sexual abuse. This article reveals that an over-protective curriculum can result in an underprotected cohort of adolescents with ID, ill-prepared to exert their sexual rights.

The conservative nature of current sexuality education for adolescents with ID further excludes those that fall outside gender and sexuality norms. To recap, the sexual knowledge provided by current curricula is heteronormative and fails to inform adolescents with ID of alternative gender, sexuality, and relationship constructs (Löfgren-Mårtenson, 2012). This results in conservative views about one's own sexuality, and low tolerance of homosexuality in others (Healy et al., 2009). Indeed, it is rare for young people with ID to identify as homosexual or bisexual (Löfgren-Mårtenson, 2009), perhaps due to the difficulties associated with creating an identity around two socially marginalised traits (Thompson, 2007). Adolescents express concerns about deviating from the norm, so they may worry a minority sexuality, in addition to ID, would make them too different (Löfgren-Mårtenson, 2009). The nexus between sexuality and ID is an example of intersectionality, that is, both the social differences interact and contribute to a greater level of social oppression or exclusion (Barnett, 2017). To remedy the social exclusion created by intersectionality, each axis of exclusion must be addressed (Meekosha, 2006). It is not enough to improve heteronormative sexuality education for adolescents with ID, as sexual minorities with ID may still be discouraged from expressing their sexuality due to social exclusion. Sexuality education must adopt a pedagogy that is more critical of gender and sexuality norms (Löfgren-Mårtenson, 2012). To increase social inclusion and uphold human rights to sexuality, sexuality education curricula for adolescents with ID needs to be less conservative.

\section{Implications \& directions for future research}

Further research is required on the knowledge and experiences of sexuality education in adolescents with ID. In kind with the studies presented herein, research should be inclusive of people with ID. Inclusive research commits to the UN goal of inclusive social 
development, and helps increase social inclusion for marginalised groups (Taket, Crisp, Graham, \& Hanna, 2014). Mirroring the findings of McDaniels and Fleming (2016), this article illustrates the need for evidence-based, population specific sexuality education curricula for adolescents with ID. While some suggestions for improved sexuality education curricula and teaching methods have been examined here, more research is required to confirm their efficacy.

The learnings gleaned from this review have important implications for policy and practice around sexuality education for adolescents with ID. Of note to the Australian community is the relevance of findings to the achievement of the National Disability Strategy via the National Disability Insurance Scheme (NDIS) currently being rolled out across the country. As recognised by the National Disability Insurance Agency (NDIA, 2017), people with disabilities have the same rights as others to participation and inclusion in all areas of life. The NDIS attempts to achieve these rights through building the capacity of individuals, mainstream services and the community through the Information, Linkages and Capacity Building (ILC) policy framework. The ILC could be a particularly useful policy tool for capacity building to remedy this article's finding that sexual education for adolescents is lacking and not socially inclusive, and moreover, seek to actively develop the required capacity across service sectors.

The review also identified a paucity of standardised measures that are currently available, and the implications this has for synthesising and comparing results across studies. Further research is needed to develop a standardised tool for measuring sexual knowledge among adolescents with ID. A standardised measure would create more cohesion across the range of studies, and enable clearer, more evidence-based comparisons between different sexuality education methods, thus strengthening researchers' ability to influence relevant public policy and practices on sexuality education for adolescents with ID. Further research also needs to be conducted to better understand how sexual knowledge differs within and across cohorts of adolescents with ID. For instance, how well sexuality education is understood by adolescents with mild ID compared to those with moderate or severe ID. This information needs to also consider which teaching modalities are most appropriate.

\section{Conclusion}

The human rights to sexuality and access to equal education for adolescents with ID are not being upheld within the current sexuality education paradigm. Sexuality education for adolescents with ID has been inconsistently effective, and only insofar as providing rudimentary knowledge on sexual anatomy, reproduction, and puberty. Sexuality education is unsuccessful in providing sexual knowledge to adolescents with ID due to the use of inappropriate teaching modalities, a lack of sexuality education outside of school programs, its focus on biological aspects of sexuality, and restrictive curricula. These factors contribute to the continued social exclusion of adolescents with ID, and hinder the realisation of their internationally recognised human right to sexuality. By detailing the perspectives of adolescents with ID, it becomes clear that further action ought to be taken to promote social justice through the design, content, and delivery of sexuality education for adolescents with ID to deliver socially inclusive outcomes on both individual and systematic levels. 


\section{References}

Ang, C. T., \& Lee, L. W. (2016). 'Sexuality education curriculum content for Malaysian students with learning disabilities', Sexuality and Disability, 34 (3): 255-267.

Australian Bureau of Statistics (ABS) (2014). 'How many people have intellectual disability?', Intellectual disability, Australia, 2012. Retrieved from

http://www.abs.gov.au/ausstats/abs@.nsf/Lookup/4433.0.55.003main+features102012

Barnard-Brak, L., Schmidt, M., Chesnut, S., Wei, T., \& Richman, D. (2014). 'Predictors of access to sex education for children with intellectual disabilities in public schools', Intellectual and Developmental Disabilities, 52 (2): 85-97.

Barnett, J. P. (2017). 'Intersectional harassment and deviant embodiment among Autistic adults: (dis)ability, gender and sexuality', Culture, Health \& Sexuality, 19 (1): 12101224.

Clarke, L. S., Haydon, T., Bauer, A., \& Epperly, A. C. (2016). 'Inclusion of students with an intellectual disability in the general education classroom with the use of response cards', Preventing School Failure: Alternative Education for Children and Youth, 60 (1): 35-42.

Corona, L. L., Fox, S. A., Christodulu, K. V., \& Worlock, J. A. (2016). 'Providing education on sexuality and relationships to adolescents with autism spectrum disorder and their parents', Sexuality and Disability, 34 (2): 199-214.

Dawood, N., Bhagwanjee, A., Govender, K., \& Chohan, E. (2006). 'Knowledge, attitudes and sexual practices of adolescents with mild retardation, in relation HIVIAIDS', African Journal of AIDS Research, 5 (1): 1-10.

Dukes, E., \& McGuire, B. E. (2009). 'Enhancing capacity to make sexuality-related decisions in people with an intellectual disability', Journal of Intellectual Disability Research, 53 (8): 727-734.

Dupras, A., \& Dionne, H. (2014). 'The concern of parents regarding the sexuality of their child with a mild intellectual disability', Sexologies: European Journal of Sexology and Sexual Health / Revue europeenne de sexologie et de sante sexuelle, 23 (4): e79e83.

Eastgate, G., Van Driel, M. L., Lennox, N., \& Scheermeyer, E. (2011). 'Women with intellectual disabilities: a study of sexuality, sexual abuse and protection skills', Australian Family Physician, 40 (4): 226.

Evans, D. S., McGuire, B. E., Healy, E., \& Carley, S. N. (2009). 'Sexuality and personal relationships for people with an intellectual disability. Part II: Staff and family carer perspectives', Journal of Intellectual Disability Research, 53 (11): 913-921.

Finlay, W. M. L., Rohleder, P., Taylor, N., \& Culfear, H. (2015). 'Understanding' as a practical issue in sexual health education for people with intellectual disabilities: A study using two qualitative methods', Health Psychology, 34 (4): 328-338.

Frawley, P., \& Wilson, N. J. (2016). 'Young people with intellectual disability talking about sexuality education and information', Sexuality and Disability, 34 (4): 469-484.

Friedman, B. D., \& Allen, K. N. (2011). 'Systems theory', in J. R. Brandell (Ed.), Theory \& practice in clinical social work (Vol. 2). Thousand Oaks, California: SAGE Publications, pp. 3-20.

Garwood, M., \& McCabe, M. P. (2000). 'Impact of sex education programs on sexual knowledge and feelings of men with a mild intellectual disability', Education \& Training in Mental Retardation \& Developmental Disabilities, 35 (3): 269-283.

Ginevra, M. C., Nota, L., \& Stokes, M. A. (2016). 'The differential effects of autism and Down's syndrome on sexual behavior', Autism Research, 9 (1): 131-140.

Gomez, M. T. (2012). 'The S words: sexuality, sensuality, sexual expression and people with intellectual disability', Sexuality and Disability, 30 (2): 237-245.

Gougeon, N. A. (2009). 'Sexuality education for students with intellectual disabilities, a critical pedagogical approach: Outing the ignored curriculum', Sex Education, 9 (3): 277-291. doi: 
Healy, E., McGuire, B. E., Evans, D. S., \& Carley, S. N. (2009). 'Sexuality and personal relationships for people with an intellectual disability. Part I: Service-user perspectives', Journal of Intellectual Disability Research, 53 (11): 905-912.

Isler, A., Beytut, D., Tas, F., \& Conk, Z. (2009). 'A study on sexuality with the parents of adolescents with intellectual disability', Sexuality and Disability, 27 (4): 229-237.

Isler, A., Tas, F., Beytut, D., \& Conk, Z. (2009). 'Sexuality in adolescents with intellectual disabilities', Sexuality and Disability, 27 (1): 27-34.

Jahoda, A., \& Pownall, J. (2014). 'Sexual understanding, sources of information and social networks; the reports of young people with intellectual disabilities and their nondisabled peers', Journal of Intellectual Disability Research, 58 (5): 430-441.

Löfgren-Mårtenson, L. (2009). 'The invisibility of young homosexual women and men with intellectual disabilities', Sexuality and Disability, 27 (1):21-26.

Löfgren-Mårtenson, L. (2012). '"I want to do it right!" A pilot study of Swedish sex education and young people with intellectual disabilities', Sexuality and Disability, 30 (2): 209225.

McDaniels, B., \& Fleming, A. (2016). 'Sexuality education and intellectual disability: Time to address the challenge', Sexuality and Disability, 34 (2): 215-225.

McGuire, B. E., \& Bayley, A. A. (2011). 'Relationships, sexuality and decision-making capacity in people with an intellectual disability', Current opinion in psychiatry, 24 (5): 398-402.

Meekosha, H. (2006). 'What the hell are you? An intercategorical analysis of race, ethnicity, gender and disability in the Australian body politic', Scandinavian Journal of Disability Research, 8 (2-3): 161-176.

National Disability Insurance Agency. (2017). A Framework for Information, Linkages and Capacity Building. Retrieved from https://www.ndis.gov.au/html/sites/default/files/lLC-Policy-Framework.pdf.

O'Callaghan, A. C., \& Murphy, G. H. (2007). 'Sexual relationships in adults with intellectual disabilities: understanding the law', Journal of Intellectual Disability Research, 51 (3): 197-206.

Plaks, M., Argaman, R., Mike Stawski, M., Qwiat, T., Polak, D., \& Gothelf, D. (2010). 'Socialsexual education in adolescents with behavioral neurogenetic syndromes', The Israel journal of psychiatry and related sciences, 47 (2): 28-34.

Pownall, J. D., Jahoda, A., Hastings, R., \& Kerr, L. (2011). 'Sexual understanding and development of young people with intellectual disabilities: mothers' perspectives of within-family context', American Journal on Intellectual and Developmental Disabilities, 116 (3): 205-219.

Pownall, J. D., Jahoda, A., \& Hastings, R. P. (2012). 'Sexuality and sex education of adolescents with intellectual disability: Mothers' attitudes, experiences, and support needs', Intellectual and Developmental Disabilities, 50 (2): 140-154.

Schalock, R. L., Borthwick-Duffy, S. A., Bradley, V. J., Buntinx, W. H., Coulter, D. L., Craig, E. M., . . . Reeve, A. (2010). Intellectual disability: Definition, classification, and systems of supports (11th ed.). Washington: American Association on Intellectual and Developmental Disabilities.

Spriggs, A. D., Mims, P. J., van Dijk, W., \& Knight, V. F. (2017). 'Examination of the evidence base for using visual activity schedules with students with intellectual disability', The Journal of Special Education, 51 (1): 14-26.

Starke, M., Rosqvist, H. B., \& Kuosmanen, J. (2016). 'Eternal children? professionals' constructions of women with an intellectual disability who are victims of sexual crime', Sexuality and Disability, 34 (3): 315-328.

Taket, A., Crisp, B. R., Graham, M., \& Hanna, L. (2014). 'Implementing the social inclusion agenda', in A. Taket, B. R. Crisp, M. Graham, L. Hanna, S. Goldingay, \& L. Wilson (Eds.), Practising social inclusion. New York: Routledge, pp. 249-256.

Thompson, S. A. (2007). 'De/centering straight talk: Queerly informed inclusive pedagogy for gay and bisexual students with intellectual disabilities', Journal of LGBT Youth, 5 (1): 37-56. 
Travers, J., Tincani, M., Whitby, P. S., \& Boutot, E. A. (2014). 'Alignment of sexuality education with self determination for people with significant disabilities: a review of research and future directions', Education and Training in Autism and Developmental Disabilities, 49 (2): 232-247.

Tissot, C. (2009). 'Establishing a sexual identity: Case studies of learners with autism and learning difficulties', Autism: the international journal of research and practice, 13 (6): 551-566.

United Nations (UN). (2008). Convention on the rights of people with disabilities and optional protocol. Retrieved from http://www.un.org/disabilities/documents/convention/convoptprot-e.pdf

United Nations Educational, Scientific and Cultural Organisation (UNESCO). (2009). International technical guidance on sexuality education: An evidence-informed approach for schools, teachers and health educators. Retrieved from http://unesdoc.unesco.org/images/0018/001832/183281e.pdf

World Health Organisation (WHO). (2017). WHO country cooperation strategy at a glance: South Africa. (WHO/CCU/17.01/South Africa). Geneva: World Health Organization Retrieved from http://www.who.int/iris/handle/10665/136874. 


\section{Biographical Notes}

Becky Rowe completed her Master of Human Services with a major in Disability Studies in 2017, graduating with Distinction. Her research builds on seven years' experience in direct disability support roles. Having grown up alongside family members with intellectual disabilities, Becky is a strong advocate for socially inclusive practices for people of all abilities. She currently resides in Melbourne and works in the sensory disability sector.

Courtney Wright is a Post-Doctoral Research Fellow at The Hopkins Centre, Griffith University. Her research has focused on four major streams relating to disability and resilience: (1) evidence-based practice; (2) consumer priorities and preferences, particularly in relation to housing; (3) housing, homelessness, and social and emotional wellbeing of First Peoples with neurocognitive and severe/profound disability; and (4) culturally safe and appropriate research methods. Dr Wright has a strong track record in knowledge translation with her research informing policy development around the National Injury Insurance Scheme (NIIS) in Queensland, practice guidelines for inclusive housing, two Commonwealth Government Inquiry submissions, and an innovative online resource for people with disability and their families. Although an avid researcher, Dr Wright has also volunteered at several Queensland-based advocacy and support organisations for people with disabilities. 